an overall attendance rate of $69 \%$. Six out of 12 questionnaires were returned.

Conclusion It may be more beneficial to complete each placement over a seven-day period. This may improve student engagement, give greater support and, where possible, encourage continuity of relationships with staff and patients. Good working relationships with the college are essential to ensure students are supported. Although no new staff were recruited, it has been agreed that we will continue to work with the college offering placements, encouraging and recruiting students who show an aptitude for hospice work.

\section{P-247 DEVELOPING WITH THE NEXT GENERATION OF HEALTH AND SOCIAL CARE PROFESSIONALS}

Annette Hart. Willen Hospice, Milton Keynes, Bucks

\subsection{6/bmjspcare-2018-hospiceabs.272}

Background Professionals at the point of registration should be confident and competent caring for patients at the end of life. Student placements include nurses, art therapists, physiotherapists, paramedics, social workers, chaplaincy and medical students

Aim What do health and social care students gain from a hospice placement?

Method Using collated student feedback 2017-2108, common themes were identified. Literature showed the development of end of life skills, frequently focuses on simulated learning (Efstathiou \& Walker, 2014). One hospice study focused only on medical students. (Greenstock, Molloy, Fiddes et al., 2013).

Results The following themes emerged:

- Inter- professional working. 'Different departments and agencies working together to provide for the patient and their family'; 'Understanding of professional boundaries'; 'Able to advise on referrals'; 'Inter-professional working, a holistic approach to deliver effective care'

- Communication skills. 'Taking part in the MDT meeting'; 'I communicate better'; 'The ability to converse more comfortably and effectively with palliative patients'; 'I can talk confidently about death dying'; 'I have developed listening skills'

- The Patient journey and its impact on caregivers. 'Getting to know patients;'; 'Seeing different stages of a journey'; 'Understanding what families go through'; 'During home visits I saw patients in their environment'

- Gaining confidence. 'Confident with symptom control medication, just in case medication, drug calculations, care in the last days of life, care after death'; 'I have learnt to preempt symptoms'; 'I recognise the signs of end of life'; 'I have learnt prescribing skills in palliative care'

- Rehabilitation palliative care. 'Social activity incorporating exercise'; 'It's not just death and dying for example, physiotherapy'.

Conclusions The students' comments directly linked with the building blocks in Ambitions for End of Life Care (2015). Students gain more than palliative care skills; respecting the skills, expertise and contributions of colleagues and teams (Francis, 2013), reflecting professional body requirements (Nursing \& Midwifery Council, 2015; Health and Care Professions Council, 2016; General Medical Council, 2014). HELP PREPARE THE NURSING WORKFORCE

Sue Griffith. Farleigh Hospice, Chelmsford, UK

\subsection{6/bmjspcare-2018-hospiceabs. 273}

Background Recent publications have made it very clear that pre-registration training is not adequately preparing nurses for end of life care (The Democratic Society, 2015; National Council for Palliative Care, 2016). Although the proposed NMC curriculum changes (Nursing \& Midwifery Council, 2017) address this for future student nurses, many nurses are already in practice without preparation, and will not benefit from curriculum change. Currently, few nurses outside of palliative care settings have access to any end of life care education (Cavaye \& Watts, 2014).

Aim To identify the attributes a prepared nurse will possess, and the antecedents of becoming prepared, with intent to inform education strategies.

Method A concept analysis using Walker and Avant's (Walker \& Avant, 2013) model was conducted to ensure rigour, and standardise the findings. Several clinical databases were searched to find appropriate literature to inform the concept analysis.

Results Attributes of a prepared nurse can be divided into two core areas; being educationally ready and having a willing attitude. The seven individual key attributes are:

- Able to assess the dying patient and plan care

- Has advanced ability to communicate with empathy

- Able to identify and manage physical symptoms

- Able to recognise and deal with dying and death

- Understands the holistic elements of dying

- Understands and is comfortable to deal with the effects of loss and bereavement on patients, families and self

- Is self-aware and self-competent.

Antecedents are: education, having a willing attitude towards the dying, exposure to death and dying, experience of care of the dying, and seeing a dead body. Empirical referents need to measure self-competence, knowledge and attitudes.

Conclusion This concept analysis will demonstrate that future education needs to be focused on those nurses who are already qualified, but lack previous end of life education. All nurses, both pre-registration and post-registration, also need to have opportunities to care for the dying, and perform care after death, in a safe environment where exposure to death can be supported.

\section{P-249 PREPARED TO CARE: CREATING A LEARNING AND COLLABORATIVE INITIATIVE TO INCREASE SUPPORT FOR MENTAL HEALTH PATIENTS WITH PALLIATIVE CARE NEEDS}

${ }^{1}$ Nicky Wood, ${ }^{2}$ Karenann Spicer, ${ }^{3}$ Jenny White, ${ }^{4}$ Arvinder Hunjan, ${ }^{5}$ Liz Haskins. ${ }^{1} /$ sabel Hospice, Welwyn Garden City, UK; ${ }^{2}$ The Hospice of St Francis, Berkhamsted, UK; ${ }^{3}$ Garden House Hospice Care, Letchworth, UK; ${ }^{4}$ Lister Hospital, Stevenage, UK; ${ }^{5}$ Herts Foundation Partnership Trust, Hatfield, UK

\subsection{6/bmjspcare-2018-hospiceabs.274}

Background Following from a successful scoping session in June 2017 in which mental health and palliative care professionals came together to look at how we can best 